\title{
RECONSTRUCTION OF THE SLIP DISTRIBUTION ALONG THE WEST HELANSHAN FAULT, NORTHERN CHINA BASED ON HIGH-RESOLUTION TOPOGRAPHY
}

\author{
Haiyun $\mathrm{Bi}^{1 *}$, Wenjun Zheng ${ }^{2}$, Qiyun Lei ${ }^{3}$, Jiangyuan Zeng ${ }^{4}$ \\ ${ }^{1}$ State Key Laboratory of Earthquake Dynamics, Institute of Geology, China Earthquake Administration, Beijing, China - \\ bihaiyun@ies.ac.cn \\ ${ }^{2}$ Guangdong Provincial Key Laboratory of Geodynamics and Geohazards, School of Earth Sciences and Engineering, Sun Yat-Sen \\ University, Guangzhou, China - zhengwenjun@mail.sysu.edu.cn \\ ${ }^{3}$ Ningxia Seismological Bureau, Yinchuan, China - leiqy624@163.com \\ ${ }^{4}$ State Key Laboratory of Remote Sensing Science, Aerospace Information Research Institute, Chinese Academy of Sciences, \\ Beijing, China - zengjy@ radi.ac.cn
}

KEY WORDS: Slip distribution, The West Helanshan Fault, High-resolution topography, Photogrammetry method, Fault behaviour

\begin{abstract}
:
The increasing wealthy of high-resolution topography allows for remotely measuring and analysing offset features and their associated surface slip distributions at a very high resolution and along a significant length of a fault, hence providing important insights into many aspects of the fault behaviour. The West Helanshan Fault is a Holocene active fault located at the junction of the Tibetan Plateau, Alashan, and Ordos blocks. Despite its special tectonic location, it has rarely been studied before. In this study, a $2-$ m-resolution DEM of the West Helanshan Fault was built from the high-resolution $(0.5 \mathrm{~m})$ WorldView-3 stereo satellite imagery based on the photogrammetry method, and a total of 181 strike-slip offsets and 201 vertical displacements were acquired along different segments of the fault. By statistical analysis of the offset observations, we conclude that at least six large paleoearthquakes have ruptured the fault, producing a minimum rupture length of $\sim 50 \mathrm{~km}$, and the paleoearthquakes have followed a characteristic slip pattern with a coseismic strike slip of $\sim 3 \mathrm{~m}$ and a vertical slip of $\sim 1 \mathrm{~m}$, corresponding to a geologic moment magnitude of 7.1 7.5.
\end{abstract}

\section{INTRODUCTION}

Detailed mapping and surveying of the offset geomorphic features and their associated surface slip distribution along a fault can guide understanding of many aspects of the fault behaviour, including the fault kinematics and mechanics, earthquake recurrence patterns, and earthquake magnitudes (Wells, Coppersmith, 1994; Zielke et al., 2010, 2012; Klinger et al., 2011; Manighetti et al., 2015; Perrin et al., 2016; Haddon et al., 2016). Following the early pioneering work of Wallace (1968, 1990), a number of studies have been conducted to measure the offsets of geomorphic markers and constrain the along-fault surface slip distributions (Sieh, 1978, 1981; Sieh, Jahns, 1984; Schwartz, Coppersmith, 1984). However, most of these early studies were based on conventional field mapping which is particularly susceptible to vegetation cover and access conditions. More recently, technologies that enable acquisition of high-resolution topographic data have become increasingly available, e.g., the terrestrial and airborne light detection and ranging (LiDAR) (Cunningham et al., 2006; Arrowsmith, Zielke, 2009; Lin et al., 2013), high-resolution satellite optical imagery (e.g., QuickBird, WorldView, and Pleiades), and the Structure from Motion (SfM) approach for DEM generation (Westoby et al., 2012; Bemis et al., 2014; Bi et al., 2017). These technologies have provided us an unprecedented opportunity to remotely measure and analyse the offset features at a very high resolution and along a significant length of a fault, thereby greatly improving both the reliability and density of the offset measurements. A number of studies have been conducted in the last few years to constrain the along-fault slip distribution of the most recent earthquake ruptures as well as the slip accumulation due to multiple earthquakes based on the LiDAR technology (Zielke et al., 2010, 2012; Salisbury et al., 2012; Manighetti et al., 2015; Haddon et al., 2016; Chen et al., 2018). However, the high costs and logistical demands of LiDAR surveys have limited its extensive application in active faulting study (Johnson et al., 2014, Zhou et al., 2015; Bi et al., 2018). Recently, a few studies have demonstrated that the photogrammetry method based on high-resolution satellite stereo imagery can provide topographic data of comparable resolution and precision to LiDAR surveys, but at significantly lower cost and with greater availability, thus becoming a very promising way for reconstruction of surface slip distribution along a fault (Zhou et al., 2015, Middleton et al., 2016, Bi et al., 2018).

The Helan Mountain (Helanshan) has a very special tectonic location. It is not only situated at the northern section of the North-South Seismic Belt in China, but also locates at the junction of the Tibetan Plateau, Alashan, and Ordos blocks (Molnar, Tapponnier, 1975; Tapponnier, Molnar, 1977; Zhang et al., 1990; Deng et al., 1996; Zhang et al., 1998; Liu et al., 2010) (Figure 1). The Helan Mountain is bounded at its eastern margin by a normal fault, the East Helanshan Fault. While on the western side of the mountain, it is bounded by a strike-slip fault, the West Helanshan Fault. However, previous studies have mostly focused on the faults located on the eastern side of the Helan Mountain or northeastern margin of the Tibetan Plateau (Deng et al., 1984; Zhang et al., 1986; Deng, Liao, 1996; Middleton et al., 2016), while the fault on the western side of the mountain has rarely been studied. Previous studies have

\footnotetext{
* Corresponding author
} 
reported that the West Helanshan Fault is a Holocene active fault (Lei, 2016; Lei et al., 2017). The fault strikes nearly northsouth and distributes on the piedmont alluvial fan at the western foot of the Helan Mountain. It extends straightly and connects with the Sanguankou-Niushoushan Fault with a right-stepping zone between them to the south and disappears into the Tengger Desert to the north, with a total length of about $90 \mathrm{~km}$ (Figure 1). According to the geometric structure, the fault has been divided into three different segments, i.e., north, middle, and south segment. It passes through the Alxa League, a relatively densely populated area in Northwestern China, and is also less than $40 \mathrm{~km}$ far from the Yinchuan city, capital of the Ningxia Hui Autonomous Region. Therefore, it is of great significance to study the behaviour this fault for future seismic hazard assessment and loss mitigation.

In this study, WorldView3 satellite imagery $(0.5 \mathrm{~m})$ was used to derive high-resolution topographic data of the faulted landforms along the fault based on the photogrammetry method. Combined with the topography derived from the Unmanned Aerial Vehicle (UAV) images based on the SfM method, we carefully identified and measured displaced geomorphic markers along different segments of the fault. By statistically analysing both the strike-slip and vertical offset measurements along the fault, we restored the rupture histories and recurrence patterns of paleoearthquakes on the fault.
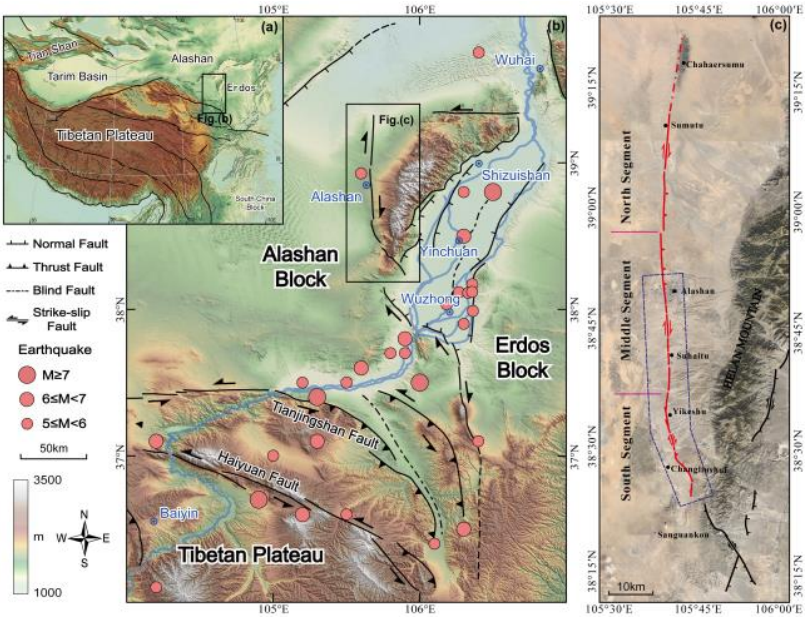

Figure 1. (a) Tectonic location of the Helan Mountain which is located at the junction of the Tibetan Plateau, Alashan, and Ordos blocks. (b) Tectonic map of the West Helanshan Fault showing the locations of major active faults and historical earthquakes $(M \geq 5)$ in surrounding areas. The base map is the 90 m SRTM (Shuttle Radar Topography Mission) hillshade map. The fault locations are modified from earlier fault maps of Tapponnier, Molnar, 1977, Zhang et al., 1986, and Deng, Liao, 1996. The seismic data are from the China Seismic Information Network (http://www.gopi.com.cn/). (c) Geometry of the West Helanshan Fault which has been divided into three different segments, i.e., north, middle, and south segment. The base map is the Google Earth image. The blue polygon indicates the coverage area of the WordView-3 satellite imagery.

\section{DATA AND METHOD}

\subsection{High-resolution Topography}

Since no archived high-resolution satellite imagery are available in the West Helanshan Fault zone, we ordered one stereo pair of WorldView-3 panchromatic images $(0.5 \mathrm{~m})$ which were acquired on 5 July 2018, covering a total area of $315 \mathrm{~km}^{2}$. It should be noted that since the north segment of the fault is covered by desert, leading the offsets unable to be well preserved in the landscape, our satellite imagery only cover the middle and south segments of the fault (Figure 1c). The WorldView-3 satellite was launched on August 13, 2014 by the Digital Globe. It operates at an altitude of $617 \mathrm{~km}$ with an inclination of $97.2^{\circ}$ and an average revisit time of $<1$ day, providing $0.31 \mathrm{~m}$ panchromatic resolution, $1.24 \mathrm{~m}$ multispectral resolution, $3.7 \mathrm{~m}$ short-wave infrared resolution, and $30 \mathrm{~m}$ CAVIS (Clouds, Aerosols, Vapors, Ice, and Snow) resolution. It is the first multi-payload, super-spectral, high-resolution commercial satellite which provides significant improvements in both image resolution and geo-positioning accuracy (Digital Global, 2014). It should be noted that though the original spatial resolution of the panchromatic images is $0.31 \mathrm{~m}$, they have been down-sampled to $0.5 \mathrm{~m}$ for commercial sales.

The stereo WorldView-3 images were processed using the Leica Photogrammetry Suite module of the ERDAS IMAGINE 2015 software. First, since the rational polynomial function (RPF) model that high-resolution satellites always use to approximate the relationship between the image space and the ground space is not a rigorous model, a total of 235 tie points, evenly distributed over the imagery, were generated to compensate for the orientation errors of the RPF model. Second, a pixel-bypixel matching procedure was performed with a search window size of $9 \times 9$ pixels and a correlation coefficient of 0.3 to 0.7 . A lot of combinations of parameters were tried and this combination was found to be a good compromise between both the density of matching points and the smoothing of topographic details. With the image coordinates of the matching points, the three-dimensional coordinates of their corresponding ground points were derived from the refined RPF model, resulting in a dense ground point cloud. Afterwards, the ground point cloud was filtered by averaging within a block of $2 \mathrm{~m}$ and then gridded with a spacing of $2 \mathrm{~m}$ using continuous curvature splines in tension and a tension factor of 0.75 . The WorldView3 imagery was finally ortho-rectified based on the generated DEM. Both the DEM and the orthophoto were geometrically corrected and projected to the WGS-84 UTM Zone 48N system. The hill-shaded DEM and the corresponding orthophoto are shown in Figure 2a and Figure 2b respectively.

It can be clearly seen that two areas along the fault are heavily covered by clouds in the WorldView-3 imagery (Region A and Region B in Figure 2a). Thus, we used a small four-rotor UAV, i.e., the Motoarsky MS670, to acquire high-resolution topographic data of these two areas based on the SfM method. The UAV is approximately $67 \mathrm{~cm}$ in diameter and has a maximum load of $5 \mathrm{~kg}$ and a flying duration of about 45 minutes. It is equipped with both a GPS and an inertial navigation system for positioning and navigation of the UAV during the flight. It also has a stabilized camera mount fitted with a Sony ILCE-QX1 camera with a fixed focal length of 16 $\mathrm{mm}$. The photographs were acquired on 27 September 2018, and the flying height of the UAV was set to $120 \mathrm{~m}$, with a $70 \%$ forward and side overlap. The total number of collected photographs is 982 , covering an area of about $0.5 \mathrm{~km} \times 3.7 \mathrm{~km}$ for region A. While for region B, the flight area is about $1.0 \mathrm{~km}$ $\times 4.3 \mathrm{~km}$ and a total of 2225 images were finally acquired. For scaling and georeferencing of the point cloud, 25 self-made markers (the size of the marker is $60 \mathrm{~cm} \times 60 \mathrm{~cm}$ ) were evenly placed in two areas as ground control points (GCP) before the flight. The three-dimensional coordinates of each GCP were measured after the flight using a Trimble R8 real-time kinematic (RTK) differential GPS system. After image acquisition, the UAV images were processed using the Agisoft PhotoScan software package. We finally obtained DEM with a high spatial 
resolution of $0.1 \mathrm{~m}$ for region $\mathrm{A}$ (Figure 2c) and region $\mathrm{B}$ (Figure 2e), and the corresponding orthophoto of region $\mathrm{A}$ (Figure 2d) and region B (Figure 2f) has a spatial resolution of $0.03 \mathrm{~m}$.

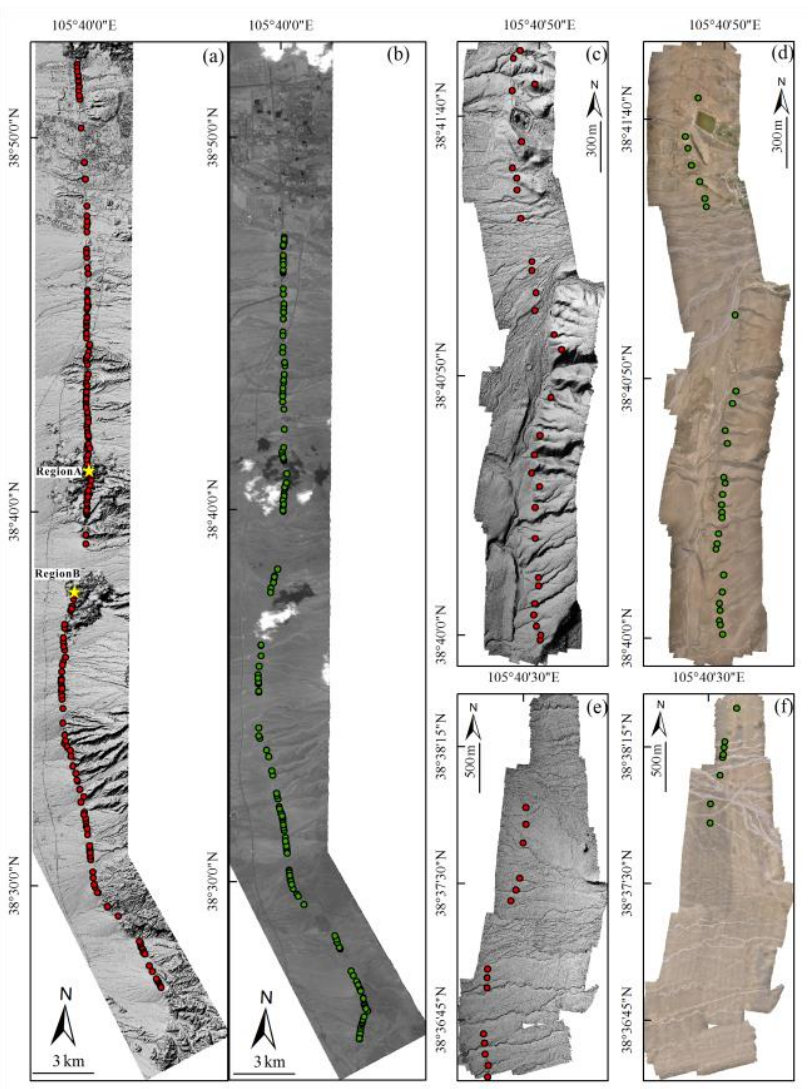

Figure 2. (a) and (b) show the hill-shaded DEM and the orthophoto of the West Helanshan Fault generated from the WorldView-3 stereo satellite imagery respectively. (c) and (d) represent the hill-shade DEM and the orthophoto of region A acquired from the UAV images respectively, while (e) and (f) represent the hill-shade DEM and the orthophoto of region B acquired from the UAV images respectively. The locations of region $\mathrm{A}$ and region $\mathrm{B}$ are illustrated in Figure $2 \mathrm{a}$ where there are heavy clouds in the satellite imagery. The green and red circles indicate the locations of strike-slip and vertical offset measurements respectively.

\subsection{Fault Offset Measurement}

The West Helanshan Fault is dominantly a strike-slip fault, but also has a small component of vertical slip. In this study, we measured both the strike slip and vertical displacement of this fault. The strike slip of the fault was measured using the socalled "back-slipping" method which aims at reconstructing the pre-earthquake morphology of the geomorphic markers (stream channels, terrace risers, etc.) that have been displaced by the fault (Figure 3). This method has been employed to measure the cumulative lateral offsets on strike-slip faults for decades (Sieh, 1978; Zielke et al. 2010, 2012; Klinger et al., 2011; Manighetti et al., 2015). To obtain the offset, we firstly identified wellpreserved displaced geomorphic markers (stream channels, terrace risers, etc.) along the fault based on the ortho-rectified high-resolution WorldView-3 imagery $(0.5 \mathrm{~m})$. Then the piercing lines of the geomorphic markers on both sides of the fault trace were mapped and projected onto the fault. Afterwards, the offsets between the projections of upstream and downstream piercing lines to the fault were measured. To determine a plausible range of the offset, different portions of the geomorphic marker were measured, e.g., measuring the thalweg as well as both edges of the stream channels. Thus for each offset measurement, it has an optimal value (Opt.offset), a minimum value (Min.offset), and a maximum value (Max.offset). The range of uncertainties might be asymmetric with respect to the optimal value, and the plus and minus uncertainties were calculated as Max.offset- Opt.offset and Opt.offset- Min.offset respectively.

The long-term vertical slip of the fault has displaced different geomorphic surfaces and formed clear fault scarps with different heights along the fault. To obtain the vertical displacement, well-preserved fault scarps that have experienced little erosion or degradation process were firstly identified based on the generated high-resolution WordView-3 DEM. Then topographic profiles were extracted across the fault scarps on different geomorphic surfaces along the fault manually. The topographic profile should follow the strike of the geomorphic surface, and vegetation and gullies should also be avoided. Afterwards, the topographic data of the hanging wall and footwall of the fault were linearly regressed by two separate straight lines respectively, which were then projected to the fault trace to estimate the vertical displacement. The root mean square error (RMSE) in fitting the lines was considered as the error of the displacement, as shown in Figure 4.
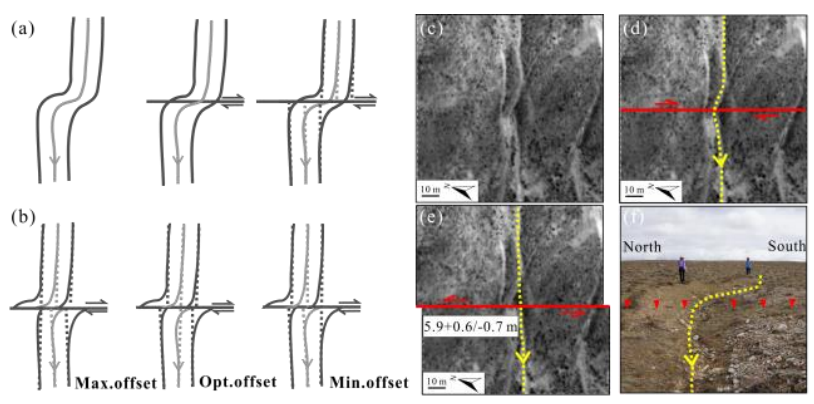

Figure 3. Measurement of strike slip using the back-slipping method, modified from Zielke et al. (2012). (a) Current morphology of a stream channel. The fault trace is outlined and both edges and the thalweg of the stream channel are projected onto the fault trace, supposing that they represent the preearthquake morphology of the channel. (b) Reconstruction of the pre-earthquake morphology of the stream channel by backslipping. Different portions (both edges and the thalweg) of the channel are aligned to determine the optimal, minimum and maximum offset value respectively. (c), (d) and (e) show an example of the back-slipping process of a stream channel that has been offset by the fault, and (f) shows the field photograph of this channel.
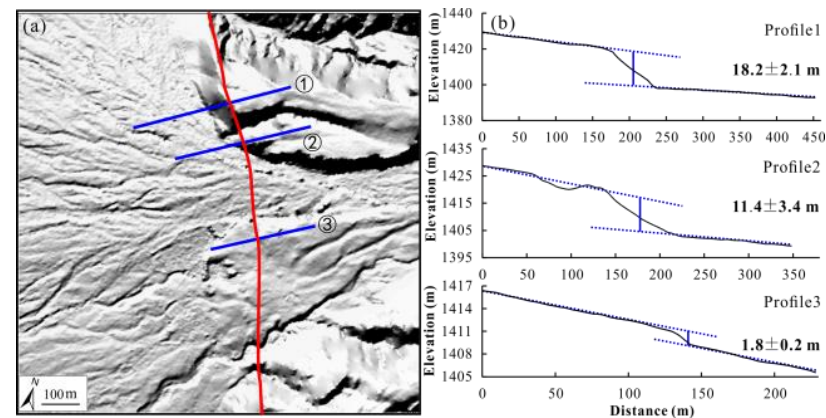

Figure 4. (a) Hill-shaded DEM of an area on the West Helanshan Fault, and the red line indicates the fault trace while the blue lines denote the selected topographic profiles. (b) 
Measurement of the vertical displacement. The upper and lower surfaces on both sides of the fault scarp are fitted by two separate lines respectively which are then projected to the fault trace to acquire the vertical displacement.

\section{RESULTS AND DISCUSSIONS}

In this study, a total of 181 strike-slip offsets and 201 vertical displacement measurements were finally acquired along the middle and south segments (about $50 \mathrm{~km}$ ) of the West Helanshan Fault. The strike-slip offsets vary from $1.7 \mathrm{~m}$ to $112.8 \mathrm{~m}$. While for the vertical displacement, the observations are between $0.5 \mathrm{~m}$ and $66.9 \mathrm{~m}$. To analyse a large amount of data with variable values and uncertainties, a probabilistic method was often adopted (Scharer et al., 2014; Manighetti et al., 2015). Following many previous studies, we adopted a Gaussian probability density function (PDF) to constrain the physically plausible range of an offset measurement (McGill, Sieh, 1991; Zielke et al., 2012; Scharer et al., 2014; Manighetti et al., 2015; Haddon et al., 2016). In this representation, each measured offset value describes the mean of a Gaussian PDF, while the standard deviation $\sigma$ of the PDF is represented by the uncertainty of the measurement. Summing the individual PDFs forms a cumulative offset probability distribution (COPD), whose dominant peaks indicate the most frequent values within the entire dataset. Provided that the peaks in the COPD correspond to frequent values of surface slip during past large earthquakes, offsets during the most recent event typically contribute to the first smallest strong peak, while the subsequent peaks in the COPD may reflect the cumulative slip of multiple preceding events (McGill, Sieh, 1991; Klinger et al., 2011; Zielke et al. 2012; Manighetti et al., 2015).

Furthermore, since different earthquakes may rupture different segments of fault and produce similar offsets, it is more reasonable to analyse the offsets separately on each individual fault segment. The surface slip distribution and the corresponding COPD plot of the slip on different segments of the West Helanshan Fault are displayed in Figures 5 to 8. It should be noted that the offsets are displayed in different range for clarity. A total of 82 strike-slip offsets and 112 vertical displacements were measured on the middle segment. It can be observed that the COPD curve of the strike-slip offsets exhibits six pronounced peaks at $2.5 \mathrm{~m}, 5.5 \mathrm{~m}, 8.8 \mathrm{~m}, 11.6 \mathrm{~m}, 14.8 \mathrm{~m}$, and $19.7 \mathrm{~m}$ in the range of $0 \sim 25 \mathrm{~m}$. Five other COPD values, at $30.5 \mathrm{~m}, 39.7 \mathrm{~m}, 51.4 \mathrm{~m}, 57.3 \mathrm{~m}$, and $90.1 \mathrm{~m}$, were relatively poorly constrained due to the limited number of offset observations in the range of 25 120 m (Figure 5). In terms of the vertical displacement, also six prominent offset peaks centered at $0.9 \mathrm{~m}, 2.2 \mathrm{~m}, 3.4 \mathrm{~m}, 4.6 \mathrm{~m}, 5.6 \mathrm{~m}$, and $6.7 \mathrm{~m}$ can be observed from the COPD plot in the range of $0 \sim 8 \mathrm{~m}$, and five other smaller COPD peaks are observed in the range of $8 \sim 60 \mathrm{~m}$ which are centered at $10.5 \mathrm{~m}, 16.4 \mathrm{~m}, 20.1 \mathrm{~m}, 27.2 \mathrm{~m}$, and 32.3 $\mathrm{m}$ respectively (Figure 6). On the south segment, a total of 99 strike-slip offsets and 89 vertical displacement measurements were finally acquired. The COPD curve of the strike-slip offsets displays six noticeable peaks in the range of $0 \sim 25 \mathrm{~m}$, which are centered at $2.6 \mathrm{~m}, 6.1 \mathrm{~m}, 9.0 \mathrm{~m}, 11.9 \mathrm{~m}, 15.4 \mathrm{~m}$, and $21.3 \mathrm{~m}$ respectively. Six other smaller COPD peaks can be observed at $27.2 \mathrm{~m}, 29.8 \mathrm{~m}, 42.8 \mathrm{~m}, 71.8 \mathrm{~m}, 89.5 \mathrm{~m}$, and $102.1 \mathrm{~m}$ in the range of $25 \sim 120 \mathrm{~m}$, which are poorly characterized due to the small number of offsets available for measurement (Figure 7). The COPD curve of the vertical displacements also exhibits six pronounced peaks, at $1.0 \mathrm{~m}, 1.8 \mathrm{~m}, 3.2 \mathrm{~m}, 4.2 \mathrm{~m}, 5.3 \mathrm{~m}$, and 6.5 $\mathrm{m}$ in the range of $0 \sim 8 \mathrm{~m}$, while four other relatively smaller COPD peaks can be found at $10.9 \mathrm{~m}, 18.0 \mathrm{~m}, 55.7 \mathrm{~m}$, and 66.0 $\mathrm{m}$ in the range of $8 \sim 80 \mathrm{~m}$ (Figure 8 ). Overall, the COPD peaks roughly tend to decay exponentially with the increasing offset amount. In fact, this decay has also been observed in many previous works (Wallace, 1968; Klinger et al., 2011; Zielke et al., 2012), which may be caused by the on-going degradation or erosion process of geomorphic features over time, leading the larger offset peaks generally unable to be well preserved in the landscape.

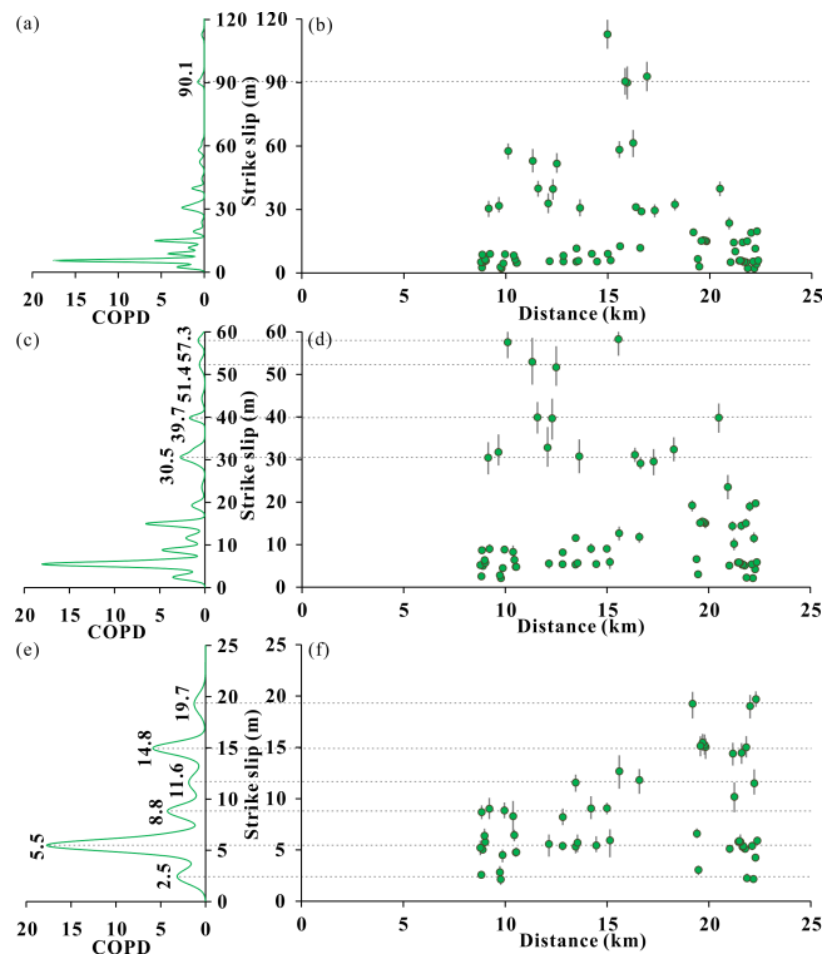

Figure 5. Strike slip on the middle segment of the West Helanshan Fault. (a), (c), and (e) represent the cumulative offset probability density (COPD) plot of the strike slip in the range of 0 120 m, 0 60 m, and 0 25 m respectively. While (b), (d), and (f) denote the distribution of the strike slip along the fault strike in the range of $0 \sim 120 \mathrm{~m}, 0 \sim 60 \mathrm{~m}$, and $0 \sim 25 \mathrm{~m}$ respectively.

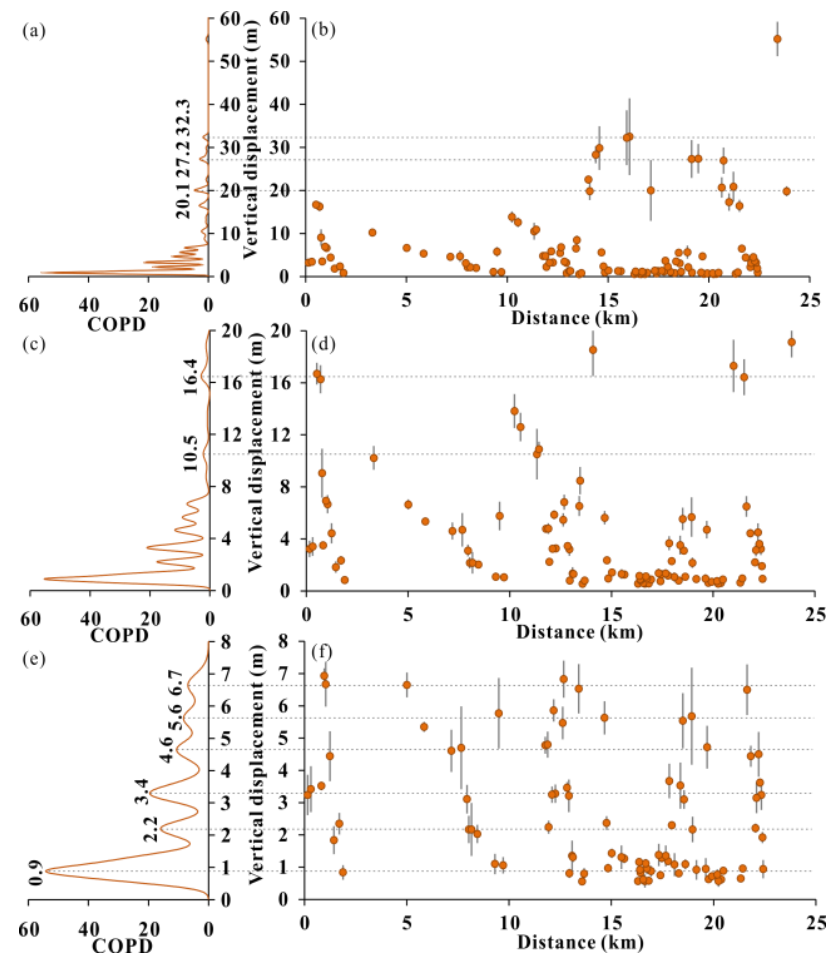


Figure 6. Vertical displacement on the middle segment of the West Helanshan Fault. (a), (c), and (e) represent the cumulative offset probability density (COPD) plot of the vertical displacement in the range of $0 \sim 60 \mathrm{~m}, 0 \sim 20 \mathrm{~m}$, and $0 \sim 8 \mathrm{~m}$ respectively. While (b), (d), and (f) denote the distribution of the vertical displacement along the fault strike in the range of 0 60 $\mathrm{m}, 0 \sim 20 \mathrm{~m}$, and 0 8 $\mathrm{m}$ respectively.

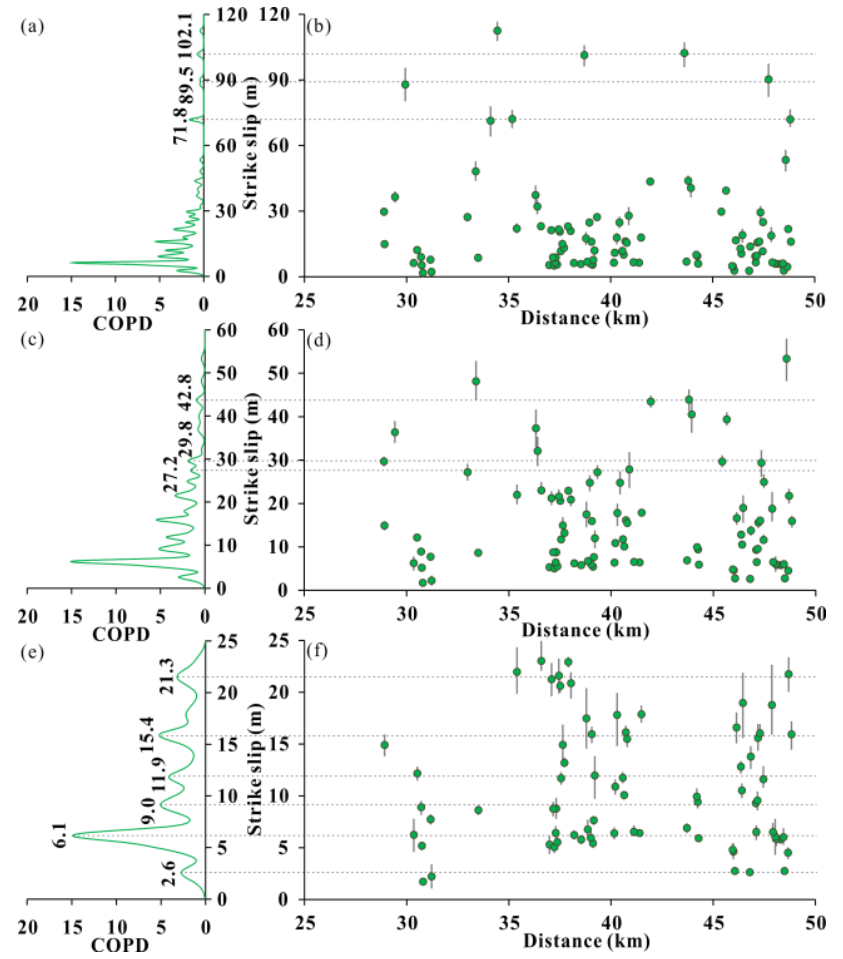

Figure 7. Strike slip on the south segment of the West Helanshan Fault. (a), (c), and (e) represent the cumulative offset probability density (COPD) plot of the strike slip in the range of 0 120 m, 0 60 m, and 0 25 m respectively. While (b), (d), and (f) denote the distribution of the strike slip along the fault strike in the range of $0 \sim 120 \mathrm{~m}, 0 \sim 60 \mathrm{~m}$, and $0 \sim 25 \mathrm{~m}$ respectively.

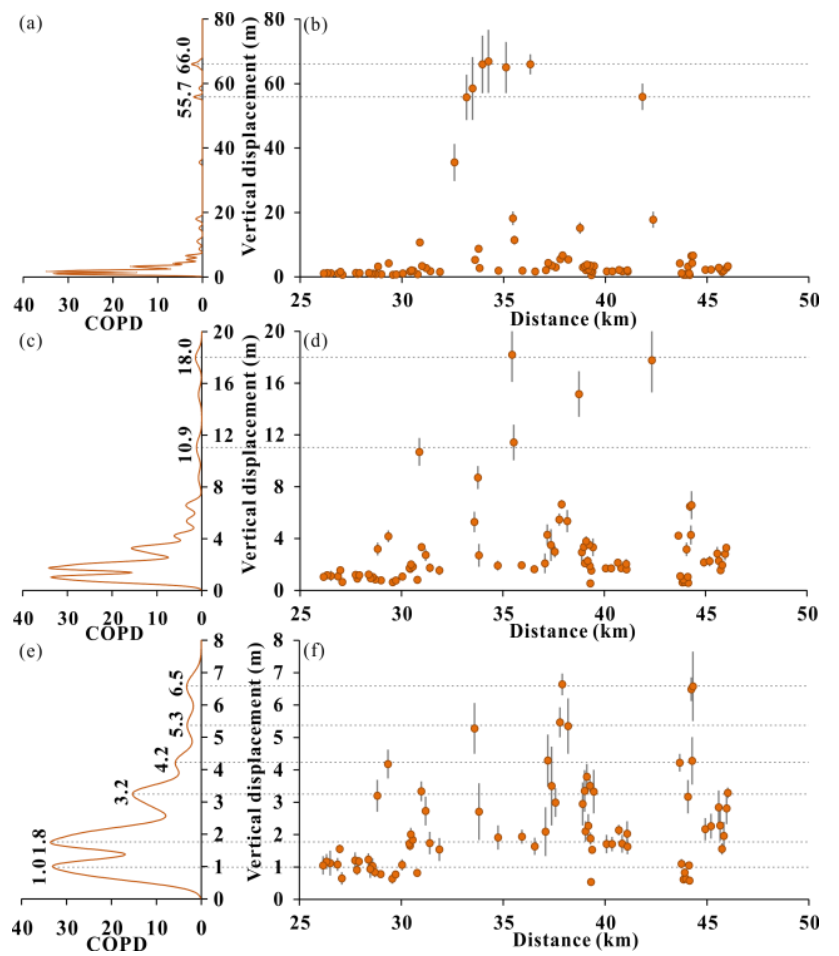

Figure 8. Vertical displacement on the south segment of the West Helanshan Fault. (a), (c), and (e) represent the cumulative offset probability density (COPD) plot of the vertical displacement in the range of $0 \sim 80 \mathrm{~m}, 0 \sim 20 \mathrm{~m}$, and $0 \sim 8 \mathrm{~m}$ respectively. While (b), (d), and (f) denote the distribution of the vertical displacement along the fault strike in the range of $0 \sim 80 \mathrm{~m}, 0 \sim 20 \mathrm{~m}$, and 0 8 $\mathrm{m}$ respectively.

Similar to many previous studies, the COPD peaks were employed to distinguish paleoearthquakes along the West Helanshan Fault in this study. However, utilizing the geomorphic records to constrain the rupture history along a fault is based on a fundamental assumption that the geomorphic markers used to measure displacement form more frequently than the surface-rupturing earthquakes that offset them (McCalpin, 2009; Zielke et al., 2012; Manighetti et al., 2015). The relatively arid climate and well-preserved landscapes combined with the comparatively slow slip rate and the millennial recurrence time of great events on the West Helanshan Fault suggest that the landscapes may provide a nearly continuous geomorphic record of recent large earthquakes along this fault (Lei, 2016; Lei et al., 2017). Thus, the smallest offset peak of the COPD plot can be attributed to the coseismic slip of the most recent event, while the successive larger offset peaks may represent the cumulative slip of multiple preceding earthquakes. In this study, we mainly focused on observations less than $25 \mathrm{~m}$ and $8 \mathrm{~m}$ for the strike slip and vertical displacement respectively, since these values are most likely reliable and well-preserved in the landscape. On the middle and south segments, the COPD plots of the strike-slip offsets both display six pronounced offset peaks $(2.5 / 2.6 \mathrm{~m}$, 5.5/6.1 m, 8.8/9.0 m, 11.6/11.9 m, 14.8/15.4 m, and 19.7/21.3 $\mathrm{m})$, and these peak values are separated by a similar amount of incremental slip, averaging $\sim 3.0 \mathrm{~m}$ (except between the fifth peak and the sixth peak where the slip increment is about 2 times of $3.0 \mathrm{~m}$ ). This incremental slip is also very similar to the slip produced by the most recent large earthquake on the fault $(2.5 / 2.6 \mathrm{~m})$. Similarly, the vertical displacements also show six prominent peaks at $0.9 / 1.0 \mathrm{~m}, 2.2 / 1.8 \mathrm{~m}, 3.4 / 3.2 \mathrm{~m}, 4.6 / 4.2 \mathrm{~m}$, $5.6 / 5.3 \mathrm{~m}$, and $6.7 / 6.5 \mathrm{~m}$ on both two segments. The resulting, clearly separated COPD peaks suggest that the vertical displacements associated with the several recent events are repeated in about $\sim 1.0 \mathrm{~m}$ increments, similar to the coseismic vertical slip of the most recent event $(0.9 / 1.0 \mathrm{~m})$. Therefore, we interpret that at least six large earthquakes have occurred repeatedly on the West Helanshan Fault to produce these measured cumulative offsets, and these large paleoearthquakes have been fairly characteristic in terms of coseismic slip along this fault, with a strike slip of $\sim 3.0 \mathrm{~m}$ and a vertical slip of $\sim 1.0$ $\mathrm{m}$. Apart from the smallest six pronounced offset peaks, we also observed several relatively large-magnitude offset peaks along both segments of the fault, which however are more poorly constrained due to the limited number of offset observations, and these offset peaks may have developed over the course of many seismic cycles. Furthermore, previous studies have found that strike-slip ruptures generally do not propagate across stepovers larger than $\sim 4 \mathrm{~km}$ (Wesnousky, 2006, 2008). Since the step-over zone between the middle and south segment is only about $2.5 \mathrm{~km}$ wide, it is unlikely to stop the propagation of earthquake ruptures on the West Helanshan Fault. Moreover, it can be observed from the COPD plots that the offset observations show very similar COPD peaks on the middle and south segments, especially the smallest six peaks which display good consistence with each other on both two segments, further suggesting that the two segments may have ruptured together in the same paleoseismic event. Following the relationship 
between moment magnitude $(M)$ and surface rupture length (SRL) for strike-slip fault, i.e., $M=5.16+1.12 * \log (S R L)$

(Wells, Coppersmith, 1994), the moment magnitude of these paleoearthquakes is estimated to be $\sim 7.1$. However, this moment magnitude may be a minimum value, since our satellite imagery only cover the middle and south segments of the fault. Furthermore, the COPD plots suggest that the average coseismic strike slip of paleoearthquakes along the West Helanshan Fault is about $\sim 3.0 \mathrm{~m}$. Based on the relationship between moment magnitude $(M)$ and average displacement $(A D)$, i.e., $M=7.04+0.89 * \log (A D)$ (Wells, Coppersmith, 1994), we can estimate the moment magnitude of these paleoearthquakes to be $\sim 7.5$. Thus, the moment magnitude of paleoearthquakes occurred along the West Helanshan Fault may be in the range of 7.1 7.5.

\section{CONCLUSIONS}

Reconstructing the surface slip distribution along a fault can guide understanding of many aspects of the fault behaviour. Especially in recent years, high-resolution topographic data sets, such as LiDAR and photogrammetric DEMs, have provided us an unprecedented opportunity to remotely measure and analyse the offset features at a very high resolution and along a significant length of a fault, thereby greatly improving both the reliability and density of the offset measurements and providing new insights into earthquake slip behaviour of the fault. However, previous works have mainly focused on reconstructing the horizontal slip distribution for strike-slip faults. In this study, both the horizontal and vertical slip distribution along the West Helanshan Fault have been constrained based on high-resolution topographic data derived from the WordView-3 stereo satellite imagery and UAV images. A total of 181 strike-slip offsets and 201 vertical displacements were acquired along the middle and south segments $(\sim 50 \mathrm{~km})$ of the fault. By statistical analysis of the offset observations, we conclude that the at least six large paleoearthquakes have occurred along the West Helanshan Fault. The earthquakes ruptured both the middle and south segments of the fault together, producing a minimum rupture length of $\sim 50 \mathrm{~km}$, and the coseismic strike slip and vertical slip of these paleoearthquakes is about $\sim 3 \mathrm{~m}$ and $\sim 1 \mathrm{~m}$ respectively, corresponding to a geologic moment magnitude of 7.1 7.5. Furthermore, both the strike-slip and vertical cumulative offsets are approximately multiples of the coseismic slip of the most recent event, suggesting that the paleoearthquakes may have followed a characteristic slip pattern along the West Helanshan Fault.

\section{ACKNOWLEDGEMENTS}

This work was supported by the National Key Research and Development Program of China (2017YFC1500101), the National Natural Science Foundation of China (41972228), the Second Tibetan Plateau Scientific Expedition and Research Program (STEP) (2019QZKK0901), and the Fundamental Research Funds in the Institute of Geology, China Earthquake Administration (IGCEA1706). Jiangyuan Zeng was supported by the Youth Innovation Promotion Association CAS (2018082).

\section{REFERENCES}

Arrowsmith, J. R., Zielke, O., 2009. Tectonic geomorphology of the San Andreas Fault zone from high resolution topography: an example from the Cholame segment. Geomorphology, 113(1), 70-81.

Bemis, S. P., Micklethwaite, S., Turner, D., James, M. R., Akciz, S., Thiele, S. T., Bangash, H. A., 2014. Ground-based and UAV-based photogrammetry: A multi-scale, highresolution mapping tool for structural geology and paleoseismology. Journal of Structural Geology, 69, 163-178.

Bi, H., Zheng, W., Ge, W., Zhang, P., Zeng, J., Yu, J., 2018. Constraining the distribution of vertical slip on the South Heli Shan Fault (northeastern Tibet) from high-resolution topographic data. Journal of Geophysical Research: Solid Earth, 123(3), 2484-2501.

Bi, H., Zheng, W., Ren, Z., Zeng, J., Yu, J., 2017. Using an unmanned aerial vehicle for topography mapping of the fault zone based on structure from motion photogrammetry. International Journal of Remote Sensing, 38(8-10), 2495-2510.

Chen, T., Liu-Zeng, J., Shao, Y., Zhang, P., Oskin, M. E., Lei, Q., Li, Z., 2018. Geomorphic offsets along the creeping Laohu Shan section of the Haiyuan fault, northern Tibetan Plateau. Geosphere, 14(3), 1165-1186.

Cunningham, D., Grebby, S., Tansey, K., Gosar, A., Kastelic, V., 2006. Application of airborne LiDAR to mapping seismogenic faults in forested mountainous terrain, southeastern Alps, Slovenia. Geophysical Research Letters, 33(20).

Deng, Q., Y. Wang, Y. Liao, W. Zhang, M. Li, 1984. Colluvial wedges and Holocene activity along the range-front fault of Helan Shan [in Chinese]. Chinese Science Bulletin, 29, 557-560. Deng, Q., Liao, Y., 1996. Paleoseismology along the rangefront fault of Helan Mountains, north central China. Journal of Geophysical Research: Solid Earth, 101(B3), 5873-5893.

DigitalGlobe, 2014. WorldView-3 datasheet. URL: https://www.spaceimagingme.com/downloads/sensors/datasheet s/DG_WorldView3_DS_2014.pdf.

Haddon, E. K., Amos, C. B., Zielke, O., Jayko, A. S., Bürgmann, R., 2016. Surface slip during large Owens Valley earthquakes. Geochemistry, Geophysics, Geosystems, 17(6), 2239-2269.

Johnson, K., Nissen, E., Saripalli, S., Arrowsmith, J. R., McGarey, P., Scharer, K., Williams, P., Blisniuk, K., 2014. Rapid mapping of ultrafine fault zone topography with structure from motion. Geosphere, 10(5), 969-986.

Klinger, Y., Etchebes, M., Tapponnier, P., Narteau, C., 2011. Characteristic slip for five great earthquakes along the Fuyun fault in China. Nature Geoscience, 4(6), 389.

Lei, Q., 2016. The extension of the arc tectonic belt in the northeastern margin of the Tibet Plateau and the evolution of the Yinchuan basin in the western margin of the north China. Doctoral dissertation. Institute of Geology, China Earthquake Administration.

Lei, Q., Zhang, P., Zheng, W., Du, P., Wang, W., Yu, J., Xie, X., 2017. Geological and geomorphic evidence for dextral strike slip of the Helan shan west-piedmont fault and its tectonic implications [in Chinese]. Seismology and Geology, 39(6), 1297-1315. 
Lin, Z., Kaneda, H., Mukoyama, S., Asada, N., Chiba, T., 2013. Detection of subtle tectonic-geomorphic features in densely forested mountains by very high-resolution airborne LiDAR survey. Geomorphology, 182, 104-115.

Liu, J., Zhang, P., Zheng, D., Wan, J., Wang, W., Du, P., Lei, Q., 2010. Pattern and timing of late Cenozoic rapid exhumation and uplift of the Helan Mountain, China. Science China Earth Sciences, 53(3), 345-355.

Manighetti, I., Perrin, C., Dominguez, S., Garambois, S., Gaudemer, Y., Malavieille, J., Matteo, L., Delor, E., Vitard, C., Beauprêtre, S., 2015. Recovering paleoearthquake slip record in a highly dynamic alluvial and tectonic region (Hope Fault, New Zealand) from airborne lidar. Journal of Geophysical Research: Solid Earth, 120(6), 4484-4509.

McCalpin, J. P., 2009. Paleoseismology. International Geophysics, Academic Press.

McGill, S. F., Sieh, K., 1991. Surficial offsets on the central and eastern Garlock fault associated with prehistoric earthquakes. Journal of Geophysical Research: Solid Earth, 96(B13), 21597-21621.

Middleton, T. A., Walker, R. T., Parsons, B., Lei, Q., Zhou, Y., Ren, Z., 2016. A major, intraplate, normal-faulting earthquake: The 1739 Yinchuan event in northern China. Journal of Geophysical Research: Solid Earth, 121(1), 293-320.

Molnar, P., Tapponnier, P., 1975. Cenozoic tectonics of Asia: effects of a continental collision. Science, 189(4201), 419-426.

Perrin, C., Manighetti, I., Ampuero, J. P., Cappa, F., Gaudemer, Y., 2016. Location of largest earthquake slip and fast rupture controlled by along-strike change in fault structural maturity due to fault growth. Journal of Geophysical Research: Solid Earth, 121(5), 3666-3685.

Salisbury, J. B., Rockwell, T. K., Middleton, T. J., Hudnut, K. W., 2012. LiDAR and field observations of slip distribution for the most recent surface ruptures along the central San Jacinto fault. Bulletin of the Seismological Society of America, 102(2), 598-619.

Scharer, K. M., Salisbury, J. B., Arrowsmith, J. R., Rockwell, T. K., 2014. Southern San Andreas fault evaluation field activity: Approaches to measuring small geomorphic offsets-Challenges and recommendations for active fault studies. Seismological Research Letters, 85(1), 68-76.

Schwartz, D. P., Coppersmith, K. J., 1984. Fault behavior and characteristic earthquakes: Examples from the Wasatch and San Andreas fault zones. Journal of Geophysical Research: Solid Earth, 89(B7), 5681-5698.

Sieh, K. E., 1978. Slip along the San Andreas fault associated with the great 1857 earthquake. Bulletin of the Seismological Society of America, 68(5), 1421-1448.

Sieh, K. E., 1981. A review of geological evidence for recurrence times of large earthquakes. Washington, DC: American Geophysical Union.

Sieh, K. E., Jahns, R. H., 1984. Holocene activity of the San Andreas fault at Wallace creek, California. Geological Society of America Bulletin, 95(8), 883-896.
Tapponnier, P., Molnar, P., 1977. Active faulting and tectonics in China. Journal of Geophysical Research, 82(20), 2905-2930. Wallace, R. E., 1968. Notes on stream channels offset by the San Andreas fault, southern Coast Ranges, California. In Conference on Geologic Problems of the San Andreas Fault System, Stanford University Publication in Geological Sciences, $11,6-21$.

Wallace, R. E., 1990. The San Andreas fault system, California. US Government Printing Office.

Wells, D.L., Coppersmith, K.J., 1994. New empirical relationships among magnitude, rupture length, rupture width, rupture area, and surface displacement. Bulletin of the Seismological Society of America, 84(4), 974-1002.

Wesnousky, S. G., 2006. Predicting the endpoints of earthquake ruptures. Nature, 444(7117), 358.

Wesnousky, S. G., 2008. Displacement and geometrical characteristics of earthquake surface ruptures: Issues and implications for seismic-hazard analysis and the process of earthquake rupture. Bulletin of the Seismological Society of America, 98(4), 1609-1632.

Westoby, M. J., Brasington, J., Glasser, N. F., Hambrey, M. J., Reynolds, J. M., 2012. 'Structure-from-Motion' photogrammetry: A low-cost, effective tool for geoscience applications. Geomorphology, 179, 300-314.

Zhang, B., Liao, Y., Guo, S., Wallace, R. E., Bucknam, R. C., Hanks, T. C., 1986. Fault scarps related to the 1739 earthquake and seismicity of the Yinchuan graben, Ningxia Huizu Zizhiqu, China. Bulletin of the Seismological Society of America, 76(5), 1253-1287.

Zhang, P., Burchfiel, B. C., Molnar, P., Zhang, W., Deng, Q., Wang, Y., Royden, L., Song, F., 1990. Late Cenozoic tectonic evolution of the Ningxia-Hui autonomous region, China. Geological Society of America Bulletin, 102(11), 1484-1498.

Zhang, Y. Q., Mercier, J. L., Vergély, P., 1998. Extension in the graben systems around the Ordos (China), and its contribution to the extrusion tectonics of south China with respect to GobiMongolia. Tectonophysics, 285(1-2), 41-75.

Zhou, Y., Parsons, B., Elliott, J. R., Barisin, I., Walker, R. T., 2015. Assessing the ability of Pleiades stereo imagery to determine height changes in earthquakes: A case study for the El Mayor-Cucapah epicentral area. Journal of Geophysical Research: Solid Earth, 120(12). 8793-8808.

Zielke, O., Arrowsmith, J. R., Ludwig, L. G., Akçiz, S. O., 2010. Slip in the 1857 and earlier large earthquakes along the Carrizo Plain, San Andreas fault. Science, 327(5969), 1119-1122.

Zielke, O., Arrowsmith, J. R., Ludwig, L. G., Akciz, S. O., 2012. High-resolution topography-derived offsets along the 1857 Fort Tejon earthquake rupture trace, San Andreas Fault. Bulletin of the Seismological Society of America, 102(3), 1135-1154.

Zielke, O., Klinger, Y., Arrowsmith, J. R., 2015. Fault slip and earthquake recurrence along strike-slip faults-Contributions of high-resolution geomorphic data. Tectonophysics, 638, 43-62. 